\title{
Demographic and prognostic factors of optic nerve astrocytoma: a retrospective study of surveillance, epidemiology, and end results (SEER)
}

Mingui Zhang ${ }^{1,2}$, Tao Chen ${ }^{3}$ and Yisheng Zhong ${ }^{1 *}$

\begin{abstract}
Background: Optic nerve astrocytomas (ONAs) are neurological neoplasms in the central nervous system (CNS), and they have the highest incidence rate among all the tumor types in the visual pathway. In this study, we conducted a Surveillance, Epidemiology, and End Results (SEER) -based research to explore the demographic, survival, and prognostic factors of patients diagnosed with ONAs.

Methods: Utilizing the SEER database, we retrospectively evaluated data of patients diagnosed with ONAs of all ages from 1984 to 2016. We used the Student's t distribution to test variables of patients and various characteristics, and Kaplan-Meier curve to illustrate overall survival (OS) with 95.0\% confidence intervals (Cls). We also performed univariate and multivariate analyses to evaluate various variables' validity on overall survival.

Results: A total of 1004 cases were analyzed, and revealed that age $(P<0.001$, hazard ratio $(H R)=8.830,95 \% \mathrm{Cl}$ : 4.088-19.073), tumor grade $(P<0.001, H R=1.927,95 \% C l: 1.516-2.450)$, diagnostic confirmation $(P<0.001, H R=2.444$, 95\% Cl: 1.632-3.660), and histology type ( $P=0.046, \mathrm{HR}=1.563,95 \% \mathrm{Cl}: 1.008-2.424)$ of the tumor were associated with decreased survival.

Conclusions: From this large, comparative study of ONAs, we found that younger age may be considered as a protective indicator, while high-grade astrocytic tumors have a worse prognosis. We also found that diagnostic confirmation and tumor grade were independent prognostic factors in this patient population.
\end{abstract}

Keywords: SEER, Optic nerve, Astrocytoma, Survival, Age

\section{Background}

In the central nervous system (CNS), there are three types of tumors: astrocytoma, oligodendroglioma, and ependymoma. Of all these tumors, astrocytoma is the most common type [1-3]. ONAs are rare astrocytic tumors that occur in the optic nerve and reach out to the chiasm and the frontal lobe frequently $[4,5]$. The

\footnotetext{
* Correspondence: yszhong68@126.com

${ }^{1}$ Department of Ophthalmology, Ruijin Hospital Affiliated Medical School, Shanghai Jiaotong University, 197 Ruijin Er Road, Shanghai 200025, China Full list of author information is available at the end of the article
}

classification of ONAs is based upon the World Health Organization (WHO) criteria, and it include Grade I (pilocytic), Grade II (diffuse), Grade III (anaplastic), and Grade IV (glioblastoma) astrocytoma [6]. Pilocytic astrocytoma has the highest incidence rate in people and it has excellent prognosis and survival rate [3, 7-10].

As $50-60 \%$ of patients with ONAs have neurofibromatosis type 1 (NF-1), the mutation in the NF-1 suppressor gene is considered to be a predictor for developing ONAs [2, 11-14]. Most patients are in the pediatric population between the ages of 0 and 14 years [15]. The

(c) The Author(s). 2021 Open Access This article is licensed under a Creative Commons Attribution 4.0 International License, which permits use, sharing, adaptation, distribution and reproduction in any medium or format, as long as you give appropriate credit to the original author(s) and the source, provide a link to the Creative Commons licence, and indicate if changes were made. The images or other third party material in this article are included in the article's Creative Commons licence, unless indicated otherwise in a credit line to the material. If material is not included in the article's Creative Commons licence and your intended use is not permitted by statutory regulation or exceeds the permitted use, you will need to obtain permission directly from the copyright holder. To view a copy of this licence, visit http://creativecommons.org/licenses/by/4.0/ The Creative Commons Public Domain Dedication waiver (http://creativecommons.org/publicdomain/zero/1.0/) applies to the data made available in this article, unless otherwise stated in a credit line to the data. 
Table 1 Demographic and clinical characteristics of optic nerve astrocytoma cases $(n=1004)$

\begin{tabular}{|c|c|c|}
\hline Characteristic & No. & $\begin{array}{l}\% \text { of } \\
\text { Total }\end{array}$ \\
\hline \multicolumn{3}{|c|}{ Age at diagnosis (years) } \\
\hline$\leq 18$ & 838 & 83.5 \\
\hline$>18$ & 166 & 16.5 \\
\hline \multicolumn{3}{|l|}{ Sex } \\
\hline Female & 520 & 51.8 \\
\hline Male & 484 & 48.2 \\
\hline \multicolumn{3}{|l|}{ Race } \\
\hline White & 833 & 83.0 \\
\hline Black & 80 & 8.0 \\
\hline Asian & 44 & 4.4 \\
\hline Other & 22 & 2.2 \\
\hline Unknown & 25 & 2.5 \\
\hline
\end{tabular}

Year of diagnosis

$<2010 \quad 616 \quad 61.4$

$\geq 2010$

$388 \quad 38.6$

Surgery performance

Surgery, NOS

16916.8

No surgery

$823 \quad 82.0$

Unknown

$12 \quad 1.2$

Tumor size

$\leq 2$

$>2$

Unknown

Diagnostic Confirmation

Radiography without microscopic confirm $\quad 674 \quad 67.1$

Clinical diagnosis only $\quad 25 \quad 2.5$

Positive histology

Positive laboratory test/marker study

Direct visualization without microscopic

confirmation

Positive microscopic confirm, method not specified

Unknown

$134 \quad 13.3$

$106 \quad 10.6$

76476.1

$281 \quad 28.0$

$1 \quad 0.1$

$6 \quad 0.6$

$2 \quad 0.2$

$15 \quad 1.5$

Tumor Extension

Unknown

$171 \quad 17$

Distant site(s)/node(s) involved

$31 \quad 3.1$

Localized only

Regional, NOS

71371.0

$89 \quad 8.9$

\section{Laterality}

Right - origin of primary

Left - origin of primary

Bilateral, single primary/paired site

$244 \quad 24.3$

Unknown
Table 1 Demographic and clinical characteristics of optic nerve astrocytoma cases $(n=1004)$ (Continued)

\begin{tabular}{lll}
\hline Characteristic & $\begin{array}{c}\text { No. } \% \text { of } \\
\text { Total }\end{array}$ \\
\hline Histology Type & & \\
Low-grade astrocytic tumors & 953 & 94.9 \\
High-grade astrocytic tumors & 11 & 1.1 \\
Astrocytoma, NOS & 40 & 4 \\
\hline
\end{tabular}

5 -year survival rate of optic nerve astrocytoma is over $95.0 \%$ [16], while more than 3 quarters of patients' vision is greatly impaired [14, 17, 18].

For a long period, ONAs were regarded as indolent diseases and did not require therapy [19]. However, the latest research suggests that ONAs have an unpredictable clinical process, ranging from rapid progression [20, 21] to spontaneous regression [22]. Some physicians had a preference for surgical treatment [23], while some tended to utilize radiotherapy treatment for ONAs patients [24]. Recently, chemotherapy and observation is believed to be an effective therapeutic method for ONAs $[25,26]$. ONAs have unpredictable progression, and the consequences are highly associated with treatment modalities, thus these facts lead to ONAs' controversial treatment choices [27].

During last decades, only a few studies had focused on the characteristics and outcomes in optic pathway gliomas in the US, but none have focused on the incidence and outcomes of ONAs in population. Sustaining observation of this disease on population is crucial. On one hand, it can help researchers evaluate the efficiency of medical care, on the other hand, it can help improves physicians' comprehension of ONAs [28, 29]. To better understand the epidemiology, age at diagnosis, racial and sex differences, histology type and diagnostic confirmation of ONAs in the US, we conducted a retrospective demographic study using the SEER database of the National Cancer Institute. SEER is an authoritative source for cancer statistics in the United States. The SEER Program provides information on cancer statistics in an effort to reduce the cancer burden among the U.S. population.

\section{Materials and methods}

Patient selection and data collection

All data were extracted from the latest SEER database with SEER*Stat software: SEER 21 (Nov 2019 release) [14]. The SEER registry provides comprehensive cancer data including incidence and survival rates which obtained from medical records, covering up approximately $30.0 \%$ of the US population $[14,30]$. Data from 1984 to 2016 and a total of 1004 patients with ONAs were extracted from the SEER database. To increase the 
Table 2 The Relationship between Age at Diagnosis and Clinical Characteristics in ONAs Patients

\begin{tabular}{|c|c|c|c|c|}
\hline Variables & $\begin{array}{l}\text { Age } \leq \\
18\end{array}$ & Age $>18$ & $\begin{array}{l}\text { Correlation } \\
\text { Coefficient }\end{array}$ & $\begin{array}{l}\mathrm{P} \\
\text { Value }\end{array}$ \\
\hline Sex & & & 0.07 & 0.026 \\
\hline Female & 425 & 95 & & \\
\hline Male & 413 & 71 & & \\
\hline Race & & & 0.057 & 0.075 \\
\hline White & 704 & 129 & & \\
\hline Black & 59 & 21 & & \\
\hline Asian & 35 & 9 & & \\
\hline Other & 19 & 3 & & \\
\hline Unknown & 21 & 4 & & \\
\hline Year of diagnosis & & & -0.002 & 0.950 \\
\hline$<2010$ & 504 & 112 & & \\
\hline$\geq 2010$ & 334 & 54 & & \\
\hline Surgery performance & & & 0.064 & 0.045 \\
\hline Surgery, NOS & 127 & 42 & & \\
\hline No surgery & 701 & 122 & & \\
\hline Unknown & 10 & 2 & & \\
\hline Tumor size & & & -0.137 & 0.034 \\
\hline$\leq 2$ & 98 & 36 & & \\
\hline$>2$ & 87 & 19 & & \\
\hline Unknown & 653 & 111 & & \\
\hline Tumor grade & & & 0.146 & $\begin{array}{l}< \\
0.001\end{array}$ \\
\hline । & 30 & 12 & & \\
\hline$\|$ & 30 & 10 & & \\
\hline III & 1 & 1 & & \\
\hline IV & 5 & 16 & & \\
\hline Unknown & 772 & 127 & & \\
\hline Diagnostic Confirmation & & & 0.099 & 0.002 \\
\hline $\begin{array}{l}\text { Radiography without } \\
\text { microscopic confirm }\end{array}$ & 588 & 86 & & \\
\hline Clinical diagnosis only & 21 & 4 & & \\
\hline Positive histology & 208 & 73 & & \\
\hline $\begin{array}{l}\text { Positive laboratory test/ } \\
\text { marker study }\end{array}$ & 1 & 0 & & \\
\hline $\begin{array}{l}\text { Direct visualization without } \\
\text { microscopic confirmation }\end{array}$ & 6 & 0 & & \\
\hline $\begin{array}{l}\text { Positive microscopic } \\
\text { confirm }\end{array}$ & 2 & 0 & & \\
\hline Unknown & 12 & 3 & & \\
\hline Tumor Extension & & & -0.011 & 0.733 \\
\hline $\begin{array}{l}\text { Distant site(s)/node(s) } \\
\text { involved }\end{array}$ & 30 & 1 & & \\
\hline Localized only & 596 & 117 & & \\
\hline Regional, NOS & 76 & 13 & & \\
\hline Unknown & 136 & 35 & & \\
\hline
\end{tabular}

Table 2 The Relationship between Age at Diagnosis and Clinical Characteristics in ONAs Patients (Continued)

\begin{tabular}{|c|c|c|c|c|}
\hline Variables & $\begin{array}{l}\text { Age } \leq \\
18\end{array}$ & Age $>18$ & $\begin{array}{l}\text { Correlation } \\
\text { Coefficient }\end{array}$ & $\begin{array}{l}P \\
\text { Value }\end{array}$ \\
\hline Laterality & & & -0.157 & $\begin{array}{l}< \\
0.001\end{array}$ \\
\hline Right - origin of primary & 214 & 65 & & \\
\hline Left - origin of primary & 205 & 39 & & \\
\hline $\begin{array}{l}\text { Bilateral, single primary/ } \\
\text { paired site }\end{array}$ & 221 & 23 & & \\
\hline Unknown & 198 & 39 & & \\
\hline Histology Type & & & 0.168 & $\begin{array}{l}< \\
0.001\end{array}$ \\
\hline $\begin{array}{l}\text { Low-grade astrocytic } \\
\text { tumors }\end{array}$ & 810 & 143 & & \\
\hline $\begin{array}{l}\text { High-grade astrocytic } \\
\text { tumors }\end{array}$ & 1 & 10 & & \\
\hline Astrocytoma, NOS & 27 & 13 & & \\
\hline
\end{tabular}

accuracy of the research, we use codes "C72.3-Optic nerve" to identify patients with optic nerve cataloged as the original tumor site [31]. Patients with ONAs were identified based on International Classification of Disease for Oncology, 3rd edition (ICD-O-3) histology codes for astrocytoma (9380, 9400-9421). Patients had another primary malignancy were excluded from our study.

To analyse data, we converted continuous variables to categorical variables. We extracted data on demographic and clinical variables, including age $(0-18$ years, $18+$ years), race [White, Black, Asian, Other (American Indian /Alaska Native /Pacific Islander), Unknown], sex (male, female), tumor grade, year of diagnosis, and survival months until death or follow-up as of December thirty-first, 2016. The study followed the SEER database manual to conduct procedures performed on patients diagnosed with ONAs [31]. In our study, surgery performances of patients were classified into 3 categories: No surgery performance; surgery not otherwise specified (Surgery, NOS), and surgery status unknown (SSU). Histology types were classified as follows: low-grade astrocytic tumors, high-grade astrocytic tumors, and astrocytoma not otherwise specified (NOS). Pilocytic astrocytoma, diffuse astrocytoma, anaplastic astrocytoma, and glioblastoma were considered as grade I, II, III, IV respectively. Grade I and grade II were deemed as low-grade astrocytic tumors, while grade III and grade IV were deemed as high-grade astrocytic tumors. The data includes both malignant and nonmalignant tumors.

Patients without complete survival information were deleted from this research. ONAs-specific survival was survival related with ONAs. 


\section{Statistical analyses}

All statistical computations in this research were conducted utilizing the IBM Statistical Package for Social Science (SPSS, Inc., Chicago, IL) Statistics software, version 20 for Mac. The Student's $t$ test or Pearson correlation test was applied to analyze quantitative variables in Table 1. Overall survival (OS) was calculated using Kaplan-Meier curves with $95 \%$ confidence intervals (CIs). If the risk factors were confirmed by univariate study, they were then adopted in multivariate Cox proportional hazard analysis. The correlation coefficient $(r)$ is the measure of degree of interrelationship between variables. A $P$ value of $<0.05$ was considered statistically significant.

\section{Results}

\section{Demographic characteristics}

In this population-based study, a total of 1004 optic nerve astrocytoma patients who were diagnosed between 1984 and 2016 were enrolled. There were 484 (48.2\%) male patients and $838(83.5 \%)$ patients who were younger than 18 years old. The average age at diagnosis is 10.9 years old. Most of the patients were white $(83.0 \%)$, while $8.0 \%$ were black and $4.4 \%$ were Asian. In this cohort, there were 953 (94.9\%) tumors categorized as low-grade astrocytic tumors and 40 (4.0\%) astrocytomas described as type NOS. Pilocytic astrocytoma was the most common histologic type with available data. Laterality information was reported for $76.4 \%$ of the patients: $27.8 \%$ of patients had a right origin of primary tumor, $24.3 \%$ had a left origin of primary tumor, and $24.3 \%$ had bilateral tumor involvement. Among all the patients, $38.6 \%$ were diagnosed in the period of $2010-2016$. The majority of patients $(82.0 \%)$ did not receive surgery. The demographic characteristics were summarized in Table 1.

There were significant statistical difference between age at diagnosis and sex $(r=0.070, P=0.026)$, surgery performance $(r=0.064, P=0.045)$, tumor size $(r=0.137, P=$ $0.034)$, tumor grade $(r=0.146, P<0.001)$, diagnostic confirmation $(r=0.099, P=0.002)$, laterality $(r=0.157, P<$ $0.001)$, and histology type $(r=0.168, P<0.001)$ (Table 2$)$. Race, year of diagnosis, and tumor extension did not result in significantly difference with age $(P=0.075, P=0.950$, $P=0.733$, respectively). Amongst patients with known tumor grade, $96.7 \%$ of patients younger than 18 years old

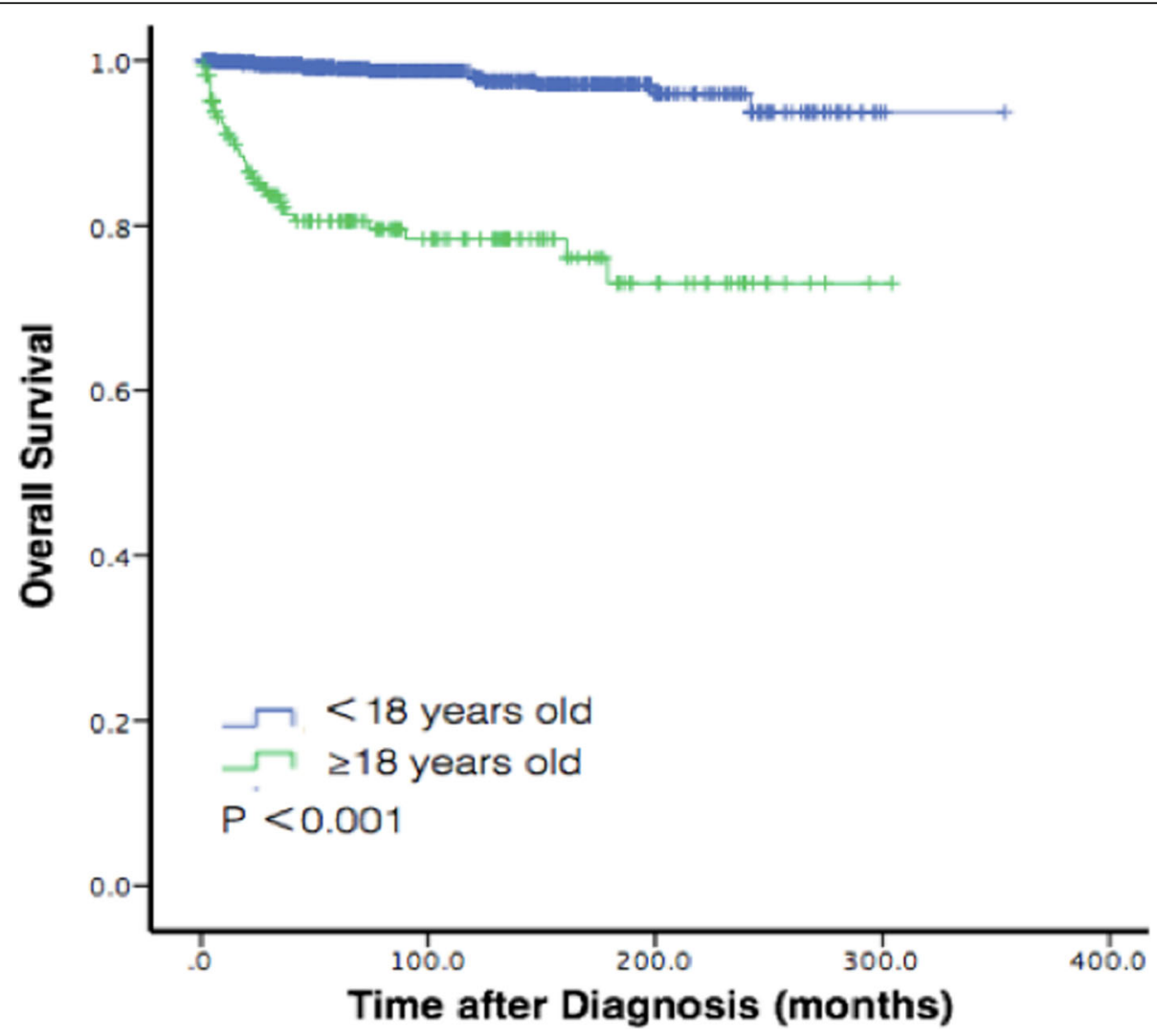

Fig. 1 Kaplan-Meier survival analysis for overall survival by age groups $0-18$ and 18+ years 
at diagnosis had low-grade astrocytic tumors $(n=810$ / 838 ); $86.1 \%$ of patients who are older than 18 years old had a low-grade astrocytic tumor $(n=143 / 166)$.

\section{Survival and prognostic factors of optic nerve astrocytoma}

The OS at 1 year, 2 years, and 5 years after diagnosis was $99.2,98.3$, and $97.1 \%$, respectively. The mean time of OS was 340.7 (95\% CI: 335.9-345.6) months. In univariate analyses, sex $(P=0.186)$, race $(P=0.633)$, year of diagnosis $(P=0.279)$, tumor size $(P=0.078)$, tumor extension $(P=0.490)$, and laterality $(P=0.127)$ were not correlated with OS by Kaplan-Meier log-rank testing. Age (Fig. 1, Fig. 2), surgery performance, tumor grade, diagnostic confirmation, and histology type were statistically significant with $\mathrm{OS}(P<0.001$, respectively). In the multivariate analyses, age $(\mathrm{P}<0.001$, hazard ratio $(\mathrm{HR})=8.830,95 \%$ CI: 4.088-19.073), tumor grade $(\mathrm{P}<0.001, \mathrm{HR}=1.927$, 95\% CI: 1.516-2.450), diagnostic confirmation ( $\mathrm{P}<$ $0.001, \mathrm{HR}=2.444,95 \% \mathrm{CI}: 1.632-3.660)$, and histology type $(P=0.046, \mathrm{HR}=1.563,95 \% \mathrm{CI}: 1.008-2.424)$ were significantly related with a decreased rate of survival after adjusting for sex, race, year of diagnosis, tumor size, tumor extension, and laterality. Patients who received surgery performance lived longer compared to those who did not, as it ( $\mathrm{HR}=5.501,95 \% \mathrm{CI}: 2.664-$ 11.358, $\mathrm{p}<0.001$ ) was associated with improved survival rate. We found surgery performance had a statistical effect on survival rate in univariate analysis, however, this phenomenon wasn't found in multivariate analysis (when all factors were included) (Table 3).

\section{Discussion}

To get a further knowledge of ONAs in patients, we conducted a retrospective study using the SEER program to evaluate the relation of various variables to ONAs. To the best of our knowledge, this current study is the largest retrospective study on ONAs. In this report, we identified 1004 cases with ONAs, diagnosed between 1984 and 2016. The results revealed a significant increase in the overall and ONAs-specific survival of ONAs of patients who were younger than 18 years old. Addition to age, tumor grade, diagnostic confirmation, and histology type were also independent prognostic factors in this patient population.

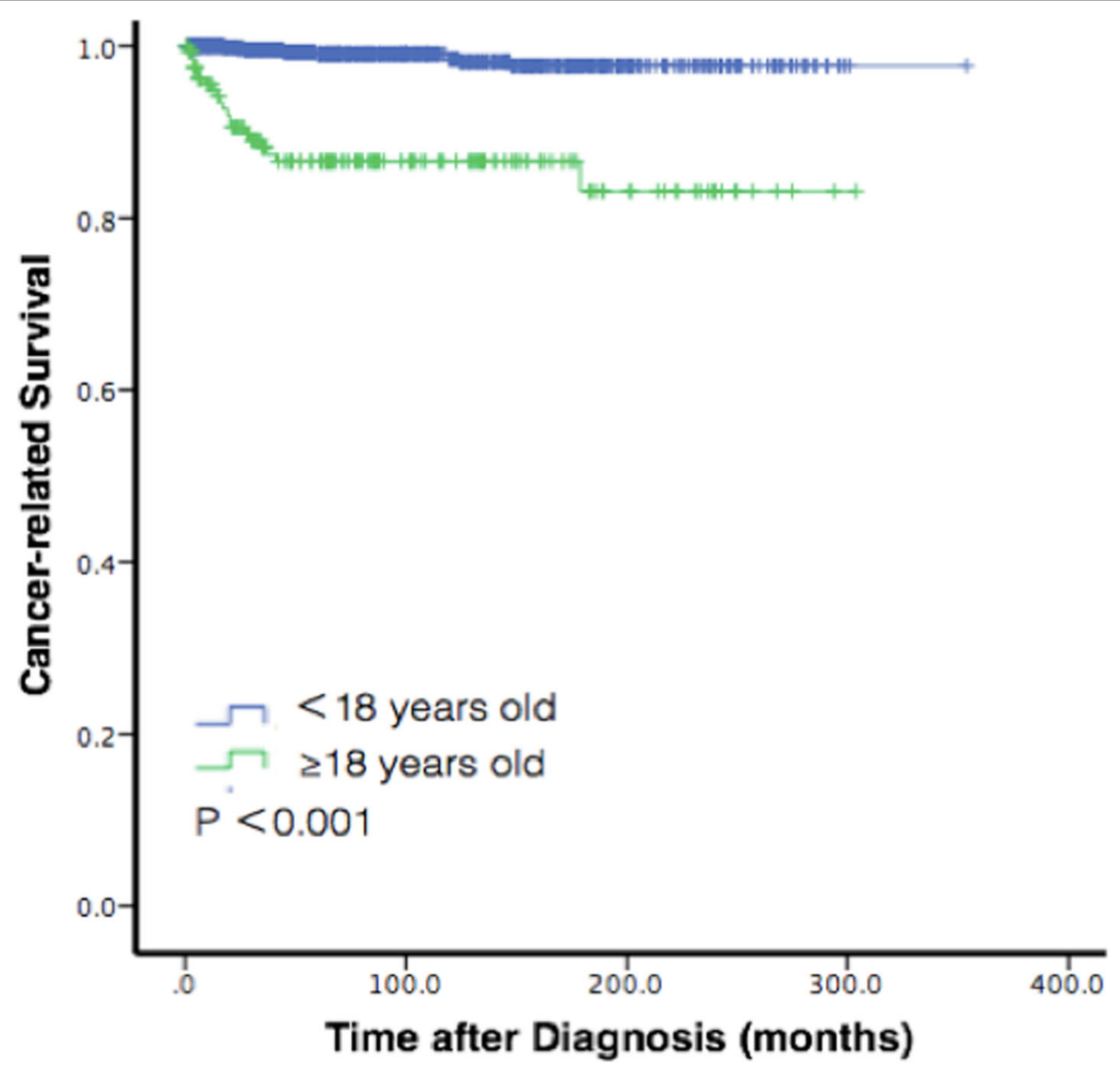

Fig. 2 Kaplan-Meier survival analysis for cancer-related survival by age groups 0-18 and 18+ years 
Table 3 Univariate and multivariate analysis of tumor-related survival

\begin{tabular}{|c|c|c|c|c|c|c|}
\hline \multirow[b]{2}{*}{ Variables } & \multicolumn{3}{|c|}{ Univariate Analysis } & \multicolumn{3}{|c|}{ Multivariate Analysis } \\
\hline & $\mathrm{HR}$ & $95 \% \mathrm{Cl}$ & $p$ Value & HR & $95 \% \mathrm{Cl}$ & $p$ Value \\
\hline $\operatorname{Age}(\geq 18,<18)$ & 11.289 & $5.284-24.122$ & $<0.001$ & 8.83 & $4.088-19.073$ & $<0.001$ \\
\hline Sex(male vs female) & 0.606 & $0.288-1.274$ & 0.186 & & / & \\
\hline Race & 1.135 & $0.675-1.908$ & 0.633 & & / & \\
\hline Year of diagnosis $(<2010, \geq 2010)$ & 0.58 & $0.216-1.556$ & 0.279 & & / & \\
\hline Surgery & 5.501 & $2.664-11.358$ & $<0.001$ & 1.452 & $0.664-3.173$ & 0.35 \\
\hline Tumor size & 4.115 & $0.854-19.815$ & 0.078 & & / & \\
\hline Tumor grade & 2.88 & $2.332-3.557$ & $<0.001$ & 1.927 & $1.516-2.450$ & $<0.001$ \\
\hline Diagnostic Confirmation & 2.436 & $1.803-3.292$ & $<0.001$ & 2.444 & $1.632-3.660$ & $<0.001$ \\
\hline Tumor Extension & 1.157 & $0.764-1.752$ & 0.490 & & / & \\
\hline Laterality & 1.296 & $0.929-1.808$ & 0.127 & & / & \\
\hline Histology & 2.654 & $1.745-4.037$ & $<0.001$ & 1.563 & $1.008-2.424$ & 0.046 \\
\hline
\end{tabular}

This study found that time of diagnosis was significantly related with survival rate. This study classified patients by age: younger thanand older than 18 years. Kaplan-Meier curves showed that the younger patients had better survival rate than the older groups, and 1year survival rates for the 2 groups were 99.9 and $94.8 \%$, respectively. The 5-year OS rates for both cohorts were 99.1 and $86.6 \%$. Tumor formation had a less aggressive progress in infants than those in older people. A previous study suggested that a more advantageous genetic background involved with tumor formation of adolescents helped increased the survival of young patients compared with older cohort [32-34]. Thus, the underlying mechanism of tumor formation in children should have further investigation, then patients of different ages and biomarkers can receive appropriate treatment.

The study also showed a statistically significant increase in ONAs incidence rate in black patients who were older than 18 years old. Even though we did not find many previous studies about the relationship between the race and the incidence rate of ONAs specifically, previous researches on race and incidence of intracranial neurological tumors had found that black population had higher incidence rate and worse survival of numerous malignant tumors $[35,36]$. Many research papers tried to explain the combination between the race and the incidence of neurological tumors, a previous article hinted that brain tumors might have different pathological classification between different races $[37,38]$.

The study illustrated an excellent OS at 5 years after diagnosis, which is $97.1 \%$ for the whole group. However, patients diagnosed with low-grade astrocytic tumors had a 5 year OS of $98.0 \%$, while the 5 year OS of patients with high-grade astrocytic tumors was $34.3 \%$. Thus, the different tumor histology type can explain the different clinical course of ONAs to a certain extent. The results of this study revealed that age of diagnosis was highly associated with tumor histology type, namely younger patients had a higher chance of being diagnosed with low-grade astrocytic tumors.

According to the information of the SEER registry, most of the patients with ONAs in US were diagnosed upon radiographic testing. Of all the 1004 patients diagnosed with ONAs, $67.1 \%$ of the whole population was diagnosed by radiography, and only $28.0 \%$ patients were diagnosed according to positive histology. The results were not unexpected to get since ONAs were tumors that were essential to the axons of the optic nerve, thus biopsy was not easily to carry out [38]. This may explain the reason why patients in the SEER program with ONAs had more chances of radiography imaging than histology, and these findings were consistent with other previous papers, whose results showed that the majority of patients were diagnosed on the basis of radiography imaging [39-41].

The limitations of this study were as follows, and lack of complete and comprehensive data collection within the SEER database should be the main reason. Even though we selected tumors located within the optic nerve, the exact locations were not recorded. A major limitation is the lack of information regarding visual outcomes. In clinic, visual outcome should be an endpoint with great importance for this disease, since the patients have an excellent overall survival. Therefore, the difference of the prognostic criterion may lead to the bias for the results. While surgery treatment is documented in the SEER information, it does not record the treatment with radiation treatment and chemotherapy in the SEER database. Chemotherapy is now considered as a prior treatment among all the choices for patients diagnosed with optic pathway gliomas, since it can delay or reduce radiation treatment $[18,42,43]$. Additionally, SEER program did not have information about tumor recurrence. A previous study showed that the complication of 
hydrocephalus was negative associated to survival rates in patients with astrocytoma [44]. However, our research couldn't evaluate the association of hydrocephalus to the patients since this outcome was not kept in the SEER database. Last but not least, there may be selection bias when information recorded in medical centers.

The SEER database dated back more than 30 years, and therapeutic plan for ONAs had developed during that period. Nowadays, surgery is considered as the firstline treatment for ONAs and radiation and chemotherapy also have changed over time [32, 45, 46]. Patients recorded in the study may have received accordingly different treatments due to different preferences.

\section{Conclusions}

This retrospective study of ONAs showed perspectives about variables that may affect survival rate. Younger age of patients seemed to be a protective factor, while patients with high-grade astrocytic tumors had a worse prognosis. Diagnostic confirmation and tumor grade were also independent prognostic factors in this patient population. More investigation is needed to look into this disease and try to find an excellent way to cure patients with this rare tumor.

\section{Acknowledgments}

None.

\section{Authors'contributions}

Conceptualization, Methodology, Data analysis, Investigation, Writing Original Draft: Mingui Zhang. Software, Writing - Review \& Editing, Visualization: Tao Chen. Writing - Review, Supervision, Project administration: Yisheng Zhong. The author(s) read and approved the final manuscript.

\section{Funding}

China Sponsorship Council.

\section{Availability of data and materials}

The dataset from SEER database generated and/or analyzed during the current study are available in the SEER dataset repository (https://seer.cancer.gov/).

\section{Declarations}

Ethics approval and consent to participate

All procedures performed in studies involving human participants were in accordance with the ethical standards of the institutional and/or national research committee and with the 1964 Helsinki declaration and its later amendments or comparable ethical standards. The informed consent was waived by Research Ethics Committee of Ruijin Hospital Affiliated to Shanghai Jiaotong University. IRB approval was exempt by the institutional review board of Ruijin Hospital Affiliated to Shanghai Jiaotong University School of Medicine.

\section{Consent for publication}

Not applicable.

\section{Competing interests}

The authors declare that they have no competing interests.

\section{Author details}

'Department of Ophthalmology, Ruijin Hospital Affiliated Medical School, Shanghai Jiaotong University, 197 Ruijin Er Road, Shanghai 200025, China. ${ }^{2}$ Department of Ophthalmology, Massachusetts Eye and Ear Infirmary / Schepens Eye Research Institute, Harvard University, Boston, MA 02114, USA.
${ }^{3}$ Department of Thoracic Surgery, Shanghai Pulmonary Hospital, Shanghai, China.

Received: 5 February 2021 Accepted: 16 August 2021

Published online: 30 August 2021

\section{References}

1. Benes $V$, Julisova I, Julis I. Our treatment philosophy of gliomas of the anterior visual pathways. Childs Nerv Syst. 1990;6(2):75-8. https://doi.org/1 $0.1007 /$ BF00307925.

2. Opocher E, Kremer LC, Da Dalt L, Wetering MD, Viscardi E, Caron HN, et al. Prognostic factors for progression of childhood optic pathway glioma: a systematic review. Eur J Cancer. 2006;42(12):1807-16.

3. Ostrom QT, Cioffi G, Gittleman H, Patil N, Waite K, Kruchko C, et al. CBTRUS statistical report: primary brain and other central nervous system tumors diagnosed in the United States in 2012-2016. Neuro-Oncology. 2019; 21(Suppl 5):v1-v100. https://doi.org/10.1093/neuonc/noz150.

4. Mudhar HS, Nuruddin M, Roy S. Primary orbital cystic Pilocytic astrocytoma. Ocul Oncol Pathol. 2016;2(4):280-4. https://doi.org/10.1159/000448006.

5. Apanisile I, Karosi T. Surgical Management of Pilocytic Astrocytoma of the optic nerve: a case report and review of the literature. Case Rep Oncol Med. 2017;2017:4283570.

6. Louis DN, Ohgaki H, Wiestler OD, Cavenee WK, Burger PC, Jouvet A, et al. The 2007 WHO classification of tumours of the central nervous system. Acta Neuropathol. 2007;114(2):97-109. https://doi.org/10.1007/s00401-007-0243-4.

7. Reis GF, Bloomer MM, Perry A. Joanna J Phillips, James P Grenert, Anthony N Karnezis and Tarik Tihan: Pilocytic astrocytomas of the optic nerve and their relation to pilocytic astrocytomas elsewhere in the central nervous system. Mod Pathol. 2013;26(10):1279-87. https://doi.org/10.1038/modpa thol.2013.79.

8. Malik A, Deb P, Sharma MC, Sarkar C. Neuropathological spectrum of pilocytic astrocytoma: an Indian series of 120 cases. Pathol Oncol Res. 2006; 12(3):164-71. https://doi.org/10.1007/BF02893364.

9. Al-Husseini MJ, Saad AM, El-Shewy KM, Nissan NE, Gad MM, Alzuabi MA et al. Prior malignancy impact on survival outcomes of glioblastoma multiforme; population-based study. Int J Neurosci. 2019;129(5):447-54. https://doi.org/10.1080/00207454.2018.1538989.

10. Farazdaghi MK, Katowitz WR, Avery RA. Current treatment of optic nerve gliomas. Curr Opin Ophthalmol. 2019;30(5):356-63. https://doi.org/10.1097/ ICU.0000000000000587.

11. Friedman JM, Birch PH. Type 1 neurofibromatosis: a descriptive analysis of the disorder in 1,728 patients. Am J Med Genet. 1997;70(2):138-43. https:// doi.org/10.1002/(SICI) 1096-8628(19970516)70:2<138:.AID-AJMG7>3.0.CO;2-U.

12. Helfferich J, Nijmeijer R, Brouwer OF, Boon M, Fock A, Hoving EW, et al. Neurofibromatosis type 1 associated low grade gliomas: a comparison with sporadic low grade gliomas. Crit Rev Oncol Hematol. 2016;104:30-41. https://doi.org/10.1016/j.critrevonc.2016.05.008.

13. King A, Listernick R, Charrow J, Piersall L, Gutmann DH. Optic pathway gliomas in neurofibromatosis type 1: the effect of presenting symptoms on outcome. Am J Med Genet A. 2003;122a(2):95-9.

14. Peckham-Gregory EC, Montenegro RE, Stevenson DA, Viskochil DH, Scheurer ME, Lupo PJ, et al. Evaluation of racial disparities in pediatric optic pathway glioma incidence: results from the surveillance, epidemiology, and end results program, 2000-2014. Cancer Epidemiol. 2018;54:90-4. https://doi. org/10.1016/j.canep.2018.04.005.

15. Shapey J, Danesh-Meyer HV, Kaye AH. Diagnosis and management of optic nerve glioma. J Clin Neurosci. 2011;18(12):1585-91. https://doi.org/10.1016/j. jocn.2011.09.003.

16. Nicolin G, Parkin P, Mabbott D, Hargrave D, Bartels U, Tabori U, et al. Natura history and outcome of optic pathway gliomas in children. Pediatr Blood Cancer. 2009:53(7):1231-7. https://doi.org/10.1002/pbc.22198.

17. Ertiaei A, Hanaei S, Habibi Z, Moradi E, Nejat F. Optic pathway gliomas: clinical manifestation, treatment, and follow-up. Pediatr Neurosurg. 2016; 51(5):223-8. https://doi.org/10.1159/000445064.

18. Kalin-Hajdu E, Decarie JC, Marzouki M, Carret AS, Ospina LH. Visual acuity of children treated with chemotherapy for optic pathway gliomas. Pediatr Blood Cancer. 2014;61(2):223-7. https://doi.org/10.1002/pbc.24726.

19. Hoyt WF, Baghdassarian SA. Optic glioma of childhood. Natural history and rationale for conservative management. Br J Ophthalmol. 1969;53(12):793-8.

20. Alvord EC Jr, Lofton S. Gliomas of the optic nerve or chiasm. Outcome by patients' age, tumor site, and treatment. J Neurosurg. 1988;68(1):85-98. 
21. Jahraus CD, Tarbell NJ. Optic pathway gliomas. Pediatr Blood Cancer. 2006; 46(5):586-96. https://doi.org/10.1002/pbc.20655.

22. Parsa CF, Hoyt CS, Lesser RL, Weinstein JM, Strother CM, Muci-Mendoza R, et al. Spontaneous regression of optic gliomas: thirteen cases documented by serial neuroimaging. Arch Ophthalmol. 2001;119(4):516-29. https://doi. org/10.1001/archopht.119.4.516.

23. Yoshikawa G, Nagata K, Kawamoto S, Tsutsumi K. Remarkable regression of optic glioma in an infant. Case illustration J Neurosurg. 2003;98(5):1134.

24. Combs SE, Schulz-Ertner D, Moschos D, Thilmann C, Huber PE, Debus J. Fractionated stereotactic radiotherapy of optic pathway gliomas: tolerance and long-term outcome. Int J Radiat Oncol Biol Phys. 2005;62(3):814-9. https://doi.org/10.1016/j.jijobp.2004.12.081.

25. Revere KE, Katowitz WR, Katowitz JA, Rorke-Adams L, Fisher MJ, Liu GT. Childhood Optic Nerve Glioma: Vision Loss Due to Biopsy. Ophthalmic Plast Reconstr Surg. 2017:33(3S Suppl 1):S107-s109.

26. Mishra MV, Andrews DW, Glass J, Evans JJ, Dicker AP, Shen X, et al. Characterization and outcomes of optic nerve gliomas: a population-based analysis. J Neuro-Oncol. 2012;107(3):591-7. https://doi.org/10.1007/s11060011-0783-2.

27. Rakotonjanahary J, Carli ED, Delion M, Kalifa C, Grill J, Doz F, et al. Rialland X and brain tumor committee of SFCE: mortality in children with optic pathway glioma treated with up-front BB-SFOP chemotherapy. PLoS One. 2015;10(6):e0127676. https://doi.org/10.1371/journal.pone.0127676.

28. Saad AM, Turk T, Al-Husseini MJ, Abdel-Rahman O. Trends in pancreatic adenocarcinoma incidence and mortality in the United States in the last four decades; a SEER-based study. BMC Cancer. 2018;18(1):688. https://doi. org/10.1186/s12885-018-4610-4.

29. Tabash MA. Characteristics, survival and incidence rates and trends of pilocytic astrocytoma in children in the United States; SEER-based analysis. J Neurol Sci. 2019;400:148-52. https://doi.org/10.1016/j.jns.2019.03.028.

30. Milano AF, Singer RB. The Cancer mortality risk project - Cancer mortality risks by anatomic site: part 1 - introductory overview; part II - carcinoma of the Colon: 20-year mortality follow-up derived from 1973-2013 (NCl) SEER*stat survival database. J Insur Med. 2017;47(2):65-94. https://doi.org/1 0.17849/insm-47-02-65-94.1.

31. Diaz-Aguilar D, ReFaey K, Clifton W, Durcanova B, Chen SG, Deen HG, et al. Prognostic factors and survival in low grade gliomas of the spinal cord: a population-based analysis from 2006 to 2012. J Clin Neurosci. 2019;61:1421. https://doi.org/10.1016/j.jocn.2018.11.025.

32. Ononiwu C, Mehta V, Bettegowda C, Jallo G. Pediatric spinal glioblastoma multiforme: current treatment strategies and possible predictors of survival. Childs Nerv Syst. 2012;28(5):715-20. https://doi.org/10.1007/s00381-012-1705-0.

33. Winters $J$, Wilson D, Davis DG. Congenital glioblastoma multiforme: a report of three cases and a review of the literature. J Neurol Sci. 2001; 188(1-2):13-9. https://doi.org/10.1016/S0022-510X(01)00538-X.

34. Wolff $B, N g$ A, Roth D, Parthey K, Warmuth-Metz M, Eyrich M, et al. Pediatric high grade glioma of the spinal cord: results of the HIT-GBM database. Neuro-Oncol. 2012;107(1):139-46. https://doi.org/10.1007/s11060-011-0718-y.

35. Barnholtz-Sloan JS, Sloan AE, Schwartz AG. Racial differences in survival after diagnosis with primary malignant brain tumor. Cancer. 2003;98(3):603-9. https://doi.org/10.1002/cncr.11534.

36. Gabriel A, Batey J, Capogreco J, Kimball D, Walters A, Tubbs RS, et al. Adult brain cancer in the U.S. black population: a surveillance, epidemiology, and end results (SEER) analysis of incidence, survival, and trends. Med Sci Monit. 2014:20:1510-7. https://doi.org/10.12659/MSM.890762.

37. Gonzalez-Quarante LH, Ruiz-Juretschke F, Sola Vendrell E, Corral OL, Agarwal V, Garcia-Leal R. Multinodular and vacuolating neuronal tumor of the cerebrum. A rare entity. New case and review of the literature. Neurocirugia (Astur). 2018:29(1):44-55.

38. Avery RA, Fisher MJ, Liu GT. Optic pathway gliomas. J Neuroophthalmol. 2011;31(3):269-78. https://doi.org/10.1097/WNO.0b013e31822aef82.

39. Hernaiz Driever $P$, Hornstein $S$, Pietsch $T$, Kortmann $R$, Warmuth-Metz $M$, Emser A, et al. Natural history and management of low-grade glioma in NF1 children. J Neuro-Oncol. 2010;100(2):199-207. https://doi.org/10.1007/s11 060-010-0159-z.

40. Tow SL, Chandela S, Miller NR, Avellino AM. Long-term outcome in children with gliomas of the anterior visual pathway. Pediatr Neurol. 2003;28(4):26270. https://doi.org/10.1016/S0887-8994(02)00628-8.

41. Fouladi M, Wallace D, Langston JW, Mulhern R, Rose SR, Gajjar A, et al. Survival and functional outcome of children with hypothalamic/chiasmatic tumors. Cancer. 2003:97(4):1084-92. https://doi.org/10.1002/cncr.11119.
42. Allen JC, Aviner S, Yates AJ, Boyett JM, Cherlow JM, Turski PA, et al. Treatment of high-grade spinal cord astrocytoma of childhood with "8-in-1" chemotherapy and radiotherapy: a pilot study of CCG-945. Children's Cancer Group. J Neurosurg. 1998;88(2):215-20. https://doi.org/10.3171/jns.1 998.88.2.0215.

43. Pizer BL, Clifford SC. The potential impact of tumour biology on improved clinical practice for medulloblastoma: progress towards biologically driven clinical trials. Br J Neurosurg. 2009;23(4):364-75. https://doi.org/10.1080/02 688690903121807.

44. Cinalli G, Sainte-Rose C, Lellouch-Tubiana A, Sebag G, Renier D, Pierre-Kahn A. Hydrocephalus associated with intramedullary low-grade glioma. Illustrative cases and review of the literature. J Neurosurg. 1995;83(3):480-5.

45. Arnautovic A, Billups C, Broniscer A, Gajjar A, Boop F, Qaddoumi I. Delayed diagnosis of childhood low-grade glioma: causes, consequences, and potential solutions. Childs Nerv Syst. 2015;31(7):1067-77. https://doi.org/10.1 007/s00381-015-2670-1.

46. Ostrom QT, Gittleman H, Liao P, Rouse C, Chen Y, Dowling J, et al. CBTRUS statistical report: primary brain and central nervous system tumors diagnosed in the United States in 2007-2011. Neuro Oncol. 2014;16(Suppl 4):iv1-63.

\section{Publisher's Note}

Springer Nature remains neutral with regard to jurisdictional claims in published maps and institutional affiliations.
Ready to submit your research? Choose BMC and benefit from:

- fast, convenient online submission

- thorough peer review by experienced researchers in your field

- rapid publication on acceptance

- support for research data, including large and complex data types

- gold Open Access which fosters wider collaboration and increased citations

- maximum visibility for your research: over $100 \mathrm{M}$ website views per year

At BMC, research is always in progress.

Learn more biomedcentral.com/submissions 